\title{
Geographic Detector-Based Spatiotemporal Variation and Influence Factors Analysis of PM2.5 in Shandong, China
}

\author{
Ming-Yang Yu, Yue Xu, Jing-Qi Li, Xiao-Chen Lu, Hua-Qiao Xing*, Ming-Liang Ma \\ School of Surveying and Geo-infomatics, Shandong Jianzhu University, Jinan 250101, China
}

Received: 4 January 2020

Accepted: 14 April 2020

\begin{abstract}
The impact of PM2.5 pollution on the ecological environment and human health and safety has attracted worldwide attention. Previous analyses of large-scale PM2.5 spatiotemporal distribution have mainly been based on satellite observations. Due to the limitations of inversion methods, the real temporal and spatial variation of PM2.5 concentrations cannot be obtained from satellite data. Using PM2.5 data from 2014 to 2017 inversed from the daily PM2.5 data in Shandong Province and employing time series, spatial autocorrelation, and geographical detector methods, the temporal and spatial evolution of PM2.5 concentrations in Shandong Province and their driving factors are revealed. The results show that the annual variation trend in the PM2.5 concentration in Shandong Province is downward, with an average annual concentration of $57.6 \mu \mathrm{g} / \mathrm{m}^{3}$, while the monthly and winter months show significant high-level u-type changes, with small changes in spring and summer, and the number of days for air compliance in 2017 was 294 . Linyi and Dezhou have the largest annual decline in air quality, while coastal cities have a small decline in air quality. From 2014 to 2017, PM2.5 of Shandong Province showed obvious spatial agglomeration and disparity patterns. The correlation between PM2.5 and other elements differs significantly by month, and soot emission has the most significant effect on PM2.5 concentration. Geographic detection analysis indicates that the main driving factors for the change in PM2.5 concentration in Shandong Province are crop broadcast area and soot emissions.
\end{abstract}

Keywords: PM2.5, spatiotemporal distribution, spatial autocorrelation, geographic detector, driving factors

\section{Introduction}

Fine particles are the most important atmospheric pollutants in China. Fine particles are responsible for both District-City and multi-level complex pollution,

*e-mail: 503293764@qq.com and their sources and causes are very complex [1]. Increased PM2.5 concentrations result in decreased atmospheric visibility and also endanger human health [2-4]. Studies show that cities with health and economic losses caused by PM2.5 are mainly distributed in the Beijing-Tianjin-Hebei region, northern and eastern regions of China and about 3 million people worldwide die each year from long-term exposure to outdoor air 
pollution [5]. In 2017, 15000 deaths in China due to short-term PM2.5 pollution, a value far exceeding the health standards of the World Health Organization (WHO). Long-term exposure to PM2.5 will cause acute, chronic bronchitis and asthma health problems, severe cases can also cause death from various causes such as cardiovascular, respiratory system, lung cancer and the like [6-8].

There are many researches on the causes and driving forces of PM2.5, including indoor and outdoor, burning wood in traditional wood stoves and fireplaces is a common heating method in rural inland areas of China and Mediterranean countries in severe cold, and residential biomass burning is the most threatening human life in indoor environments [9-11]. In addition, other pollutants in the outdoor atmosphere, topographical conditions, socioeconomic factors and various meteorological factors affect PM2.5 concentration, resulting in significant spatial and temporal variability and spatial spillover [12-14], Meteorological factors include temperature, humidity, precipitation, wind speed, and horizontal visibility [15]. Terrain factors include topographic fluctuations, slopes, and aspects, and many scholars have conducted the correlation analysis between PM2.5 and other pollutants such as $\mathrm{PM} 10, \mathrm{SO}_{2}, \mathrm{O}_{3}, \mathrm{NO}, \mathrm{CO}$, etc $[16,17]$. Economic factors include urban population density, urban greening rate, building area ratio, motor vehicle exhaust emissions, straw burning, coal burning, land use types, steel manufacturing [18]. Zhou et al. (2017) used geographic detectors to analyze the socio-economic factors that drive the temporal and spatial changes of PM2.5, they found that population density, industrial soot and straw burning were the main factors for the spatial change of PM2.5 concentration in China [19].

Researches on air pollution are more developed in North America, Europe and other developed regions, which mainly focusing on health benefits, affecting heterogeneity, spatio-temporal variability, and economic growth [20-22]. With the acceleration of urbanization and rapid industrialization in China, more scholars pay attention to the sources and characteristics of air pollutants in China. Some scholars use time series, multiple regression models, and geographic weighted models to study the distribution of PM2.5 over time [23-25]. For example, Fu et al. (2016) estimated the concentrations of PM2.5 and PM10 in Xinjiang using least squares and geographic weighted regression models, the geographic weighted regression model has a good fit and small error as a result, which can clearly reflect the spatial distribution of the concentration [26]. Han et al. (2019), Wang et al. (2015) and Guo et al. (2009) have also analyzed the distribution of PM2.5 in space using spatial autocorrelation and interpolation analysis and remote sensing inversion [27-29]. Zhang et al. (2016), Jin et al. (2013) and Jiang et al. (2017) have used the correlation analysis method, gray correlation method, spatial lag model, spatial error model, and spatial Dubin model to analyze the main influencing factors of PM2.5 [30-32]. These studies above analyzed the temporal and spatial distribution and driving forces of PM2.5 in different aspects with vary methods, which have a great significance to guide the specific protective measures required for air pollution.

Currently, there are three ways to obtain the PM2.5 concentration, namely, real-time monitoring point data spatial interpolation, remote sensing image inversion of atmospheric aerosol thickness (AOD) and the establishment of a weighted regression model [33]. It is difficult to use satellite inversion telemetry AOD to characterize the spatial pollution pattern of PM2.5 to reveal the variation pattern of a certain region on different time scales $[34,35]$. Therefore, studying spatial and temporal heterogeneity in Shandong Province using near-surface observation data will provide more scientific and accurate results. In 2017, the Ministry of Environmental Protection of China announced the air quality status of China's key regions and 74 cities in 2014 based on the comprehensive ranking of PM2.5, PM10, $\mathrm{NO}_{2}, \mathrm{CO}, \mathrm{O} 3$ and other pollutants [36]. Among them, Jinan City in Shandong ranks among the top ten cities with poor air quality. The air quality in Shandong Province is becoming increasingly severe, but there are rarely researches in Shandong Province, we use the observation data of monitoring stations to study the source analysis, the genetic mechanism, spatial characteristics and driving factors of PM2.5 in Shandong Province from 2014 to 2017. The time series analysis method is used to analyze the seasonal, monthly and autocorrelation of PM2.5 concentration in Shandong Province, and the temporal variation of PM2.5 concentrations in Shandong Province is discussed. In addition to spatial statistical analysis (global Moran's I and Anselin local Moran's I) methods, the spatial distribution and spatial evolution characteristics of PM2.5 concentration values in Shandong Province from 2015 to 2017 are studied by means of spatial interpolation. To solve the problem of driving factors, we adopt a novel method called a geographic detector. Geographical detectors have shown state-of-the-art performance in the field of air pollution, These detectors can detect not only the impact of each factor on PM2.5 but also the interaction between two factors.This study can help understand the scale of pollution and make decision support for improving air quality in Shandong Province.

\section{Materials and Methods}

\section{Research Area}

Shandong, referred to as "Lu", is a provincial administrative region located on the eastern coast of China between $34^{\circ} 22.9^{\prime}-38^{\circ} 24.01^{\prime}$ north latitude and $114^{\circ} 47.5^{\prime}-122^{\circ} 42.3^{\prime}$ east longitude. It borders Hebei, Henan, Anhui and Jiangsu provinces with a total area of 157100 square kilometers. (Fig. 1). 


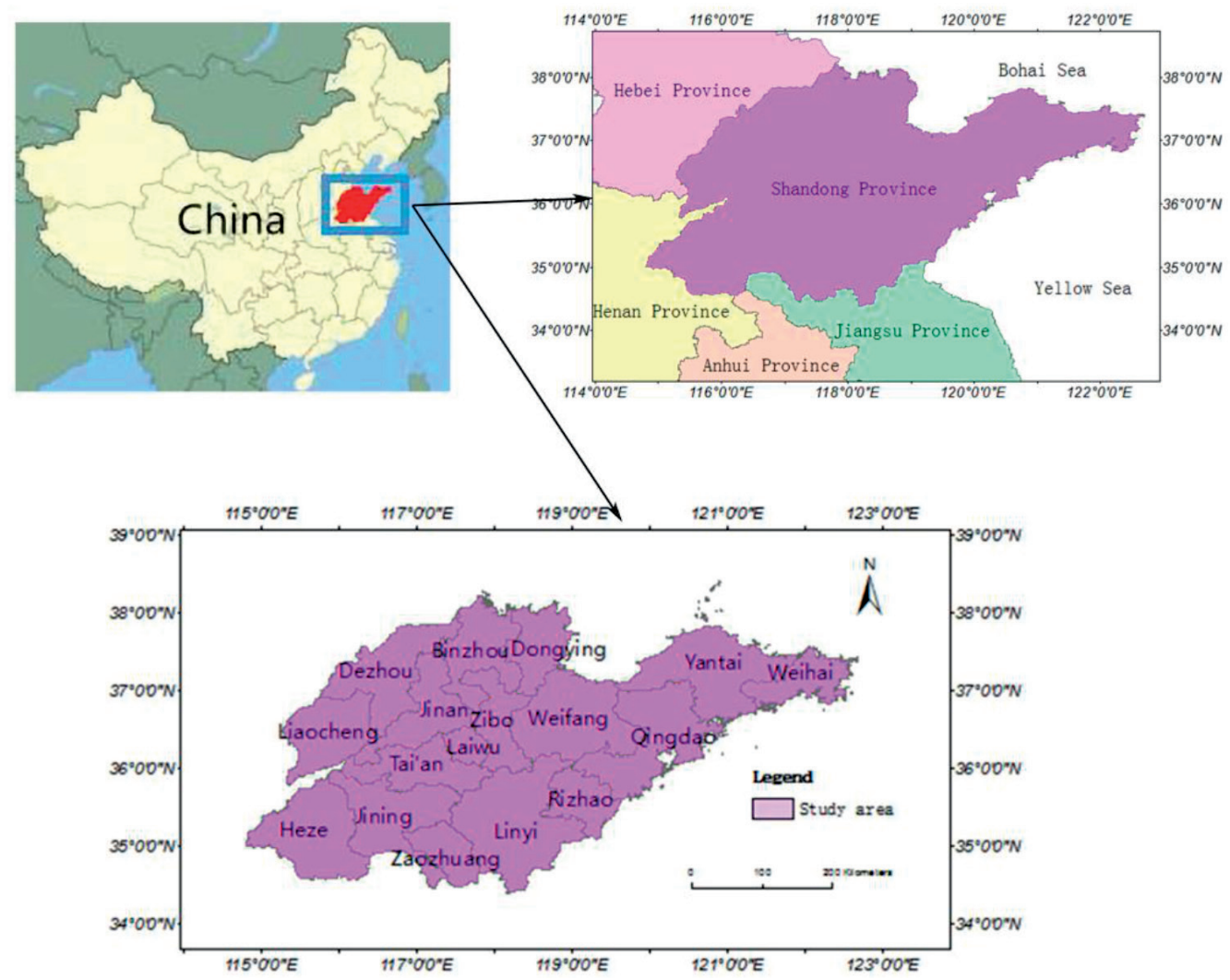

Fig. 1. The Location of the research area.

\section{Materials}

Three types of research data are used. (1) The daily monitoring values of atmospheric pollutants in 17 cities in Shandong Province from 2014 to 2017 are obtained from the China Air Quality Online Monitoring Platform (https://www.aqistudy.cn/historydata/). (2) Based on the basic geographic data, the regional vector boundaries of Shandong Province are extracted from the administrative boundaries of provinces and municipalities. (3) Social and economic data are derived from the Shandong Statistical Yearbook from the corresponding years (2014-2017).

\section{Methods}

\section{Time Series Analysis Method}

Autocorrelation analysis is a commonly used method of time series analysis [37]. The autocorrelation analysis method was used to analyze the daily average PM2.5 concentration data continuously observed in Shandong Province from 2014 to 2017, to explore its change process and development scale, and to determine the monitoring period according to the time variation characteristics of the detected objects. This paper studies the annual and quarterly changes in PM2.5 in Shandong Province from 2014 to 2017. The formulas for calculating the sample autocorrelation function (ACF) of the time series are as follows:

$$
r_{k}=\frac{\sum_{t=1}^{n}\left(x_{t}-\bar{x}\right)\left(x_{t+k}-\bar{x}\right)}{\sum_{t=1}^{n}\left(x_{t}-\bar{x}\right)^{2}}
$$

...where $r_{k}$ represents the time series autocorrelation coefficient, $\mathrm{t}$ represents the sequence, $\mathrm{k}$ represents the time lag, $\mathrm{n}$ represents the sample path length, $\mathrm{x}_{\mathrm{t}}$ represents the PM2.5 concentration on day t, and $\overline{\mathrm{X}}$ is the average of $x_{t}$. The mean value of a variable is defined by (2):

$$
\bar{x}=\frac{1}{n} \sum_{t=1}^{n} x_{t}
$$

Formulas (1) and (2) can be used to calculate the self-correlation coefficient of the PM2.5 concentration in Shandong Province with time and to draw relevant conclusions from their ACF diagrams.

\section{Spatial Autocorrelation Analysis}

The global spatial autocorrelation of the PM2.5 concentration was tested by the global Moran's I index. The value of global Moran's I index is between -1 and 1: a value less than 0 indicates a negative correlation [38]. The smaller the value is, the stronger the spatial 
dispersion of PM2.5; a value equal to 0 is irrelevant and indicates that the space is random; a value greater than 0 means positive correlation, and a larger value indicates that PM2.5 has a strong spatial agglomeration [39]. The calculation formula of the global Moran's I index (3) is as follows:

$$
\begin{gathered}
I=\frac{\sum_{i=1}^{n} \sum_{j=1}^{n} W_{i j}\left(x_{i}-\bar{x}\right)\left(x_{j}-\bar{x}\right)}{S^{2} \sum_{i=1}^{n} \sum_{j=1}^{n} W_{i j}} \\
S=\frac{1}{n} \sum_{i=1}^{n}\left(x_{i}-\bar{x}\right)^{2}
\end{gathered}
$$

...where $\mathrm{n}$ is the sample size, that is, the number of spatial locations. $x_{i} x_{j}$ are observation values of spatial location (region) $\mathrm{i}$ and $\mathrm{j}$, respectively, and $W_{i j}$ indicates that the spatial relationship weight matrix is used to display the proximity relationship of spatial positions $\mathrm{i}$ and $\mathrm{j}$. When $\mathrm{i}$ and $\mathrm{j}$ are adjacent positions (regions), $W_{i j}=1$; conversely, $W_{i j}=0$. The global Moran's I has a value range of $[-1,1]$.

$$
Z(I)=\frac{I-E(I)}{\sqrt{\operatorname{VAR}(I)}}
$$

In the formula, $\mathrm{Z}(\mathrm{I})$ can measure the salience level of the global Moran's I index, e(i) is the mathematical expectation, and var(i) is the variance [40].

The advantage of local spatial autocorrelation analysis is that the local spatial autocorrelation of each spatial location can be clearly obtained through the saliency map. For the i-th spatial element, the Moran's I index (5) formula is as follows:

$$
I_{i}=\frac{\left(X_{i}-X\right)}{S^{2}} \sum_{j} W_{i j}\left(X_{j}-\bar{X}\right)
$$

$\mathrm{Z}(\mathrm{I})$, which measures the significance level of the global Moran's I index, can also measure the local Moran's I index. In the case of $\mathrm{P}=0.05$, if $\mathrm{Z}(\mathrm{I})>1.96$, the concentration of PM2.5 in this unit and its adjacent units is relatively high, and it is the "high-high" type, i.e., "hot spot" area; if $\mathrm{Z}(\mathrm{I})>1.96$, the concentration of PM2.5 in this unit and its adjacent units is relatively low, and it is the "low-low" type, that is, a "cold spot" area; if $\mathrm{Z}(\mathrm{I})<-1.96$, the high-PM2.5 concentration units are surrounded by the low-value units, and it is the "high-low" type; if $\mathrm{Z}(\mathrm{I}) \leq 1.96$, the low-PM2.5 concentration units are surrounded by the high-value units, and it is a "low-high" type, where $\mathrm{Z}(\mathrm{I})>1.96$ indicates that there is a significant positive local spatial correlation and spatial aggregation; for $Z(I) \leq 1.96$, there is a significant negative local spatial correlation, and the space is discrete.

\section{Geographic Detector}

Geographic detectors can detect spatial heterogeneity by checking the consistency of the spatial distribution of two variables and ultimately detecting the possible causal relationship between the two variables [41]. A factor detector is used in this model to detect whether a geographical factor is the cause of the difference in PM2.5 spatial distribution. The specific method is to compare the total variance of PM2.5 indicators by different categories and then compare the total variance of indicators in the entire region. The model (6) is as follows:

$$
P_{D . H}=1-\frac{1}{n \sigma_{H}^{2}} \sum_{i=1}^{n} n_{D J} \sigma \frac{2}{H_{D J}}
$$

$\mathrm{P}_{\mathrm{D} . \mathrm{H}}$ is the explanatory force of the PM2.5 driving factor; D is the driving factor of the PM2.5 average concentration change; $\mathrm{n}$ and $\sigma^{2}$ are the total sample size and variance of the study area; $\mathrm{n}$ is the classification number of some driving factors; $\mathrm{n}_{\mathrm{Dj}}$ is the sample number of $\mathrm{D}$ index in class $\mathrm{I}$. The range of $\mathrm{P}_{\mathrm{D} . \mathrm{H}}$ is $[0,1]$. The larger the value, the stronger the explanatory power of this factor for the change in PM2.5 concentration. A value of 0 indicates that the classification factor has nothing to do with the change in PM2.5 A value of 1 indicates that the classification factor can fully explain the difference characteristics of PM2.5.

\section{Results and Discussion}

\section{Time Variation of PM2.5 in Shandong Province}

\section{PM2.5 Yearly and Monthly Changes}

According to the comprehensive time series analysis, the PM2.5 concentration of each city in Shandong Province shows a downward trend in four years as a whole (Fig. 2), and the PM2.5 in Shandong Province also shows a downward trend in 2014-2017. Among them, Linyi and Dezhou have the largest annual decline in the concentration, reaching an annual decline of $12-13 \mu \mathrm{g} / \mathrm{m}^{3}$, while the eastern coastal cities have the lowest decline in the concentration. In 2017, the number of days of PM2.5 moderate pollution and heavy pollution in 17 cities has greatly improved compared with that in 2015 (Fig. 3). The weather of Heze and Laiwu with more serious pollution reached more than half a month in December 2015 is moderate pollution and heavy pollution, and it dropped to less than 15 days in 2017. Yantai and Weihai are the cities with the best weather conditions. In 2017, In 2017, Qingdao and Rizhao were also in good condition, with moderate and severe pollution days less than 5 days. In 2014-2017, the tendency of the monthly concentration of PM2.5 in Shandong Province showed a 'U'-type 


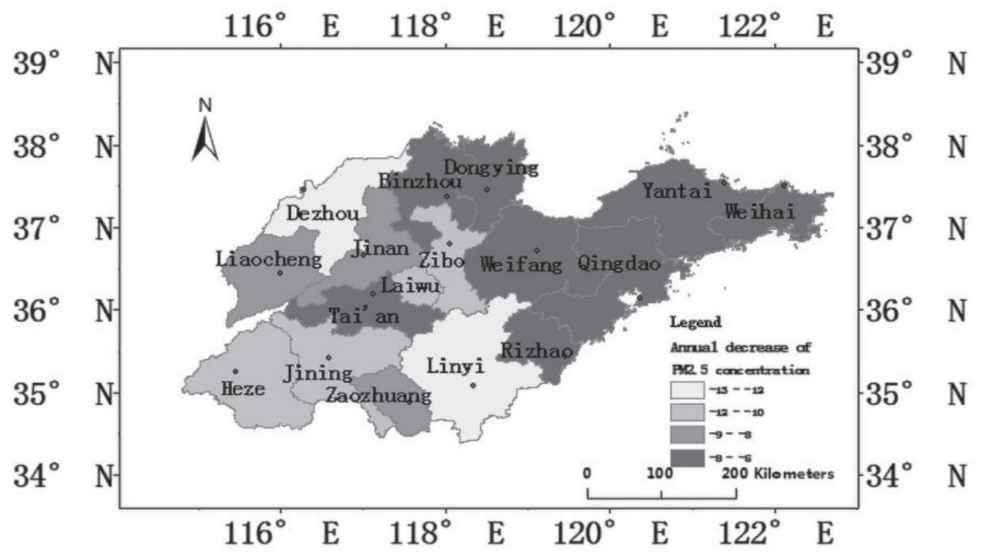

Fig. 2. Distribution map of PM2.5 annual average concentration reduction in 17 cities and regions from 2014 to 2017.

fluctuation (Fig. 4). The highest concentrations in 2014 and 2015 amounted to $136 \mu \mathrm{g} / \mathrm{m}^{3}$ and $137 \mu \mathrm{g} / \mathrm{m}^{3}$, respectively, which appeared in January and December, respectively. In August, PM2.5 had the lowest monthly average concentration, which was lower than the standard concentration limit of $75 \mu \mathrm{g} / \mathrm{m}^{3}$. The lowest concentration was $33 \mu \mathrm{g} / \mathrm{m}^{3}$ in August 2017, which was below the $35 \mu \mathrm{g} / \mathrm{m}^{3}$ standard line. The overall PM2.5 concentration over the whole year showed a U-shaped trend, with low values in summer and autumn and high values in spring and winter. The foremost reason is that the amount of coal used for heating in winter increases, and the amount of particulate matter discharged into the atmosphere increases. In summer, the temperature

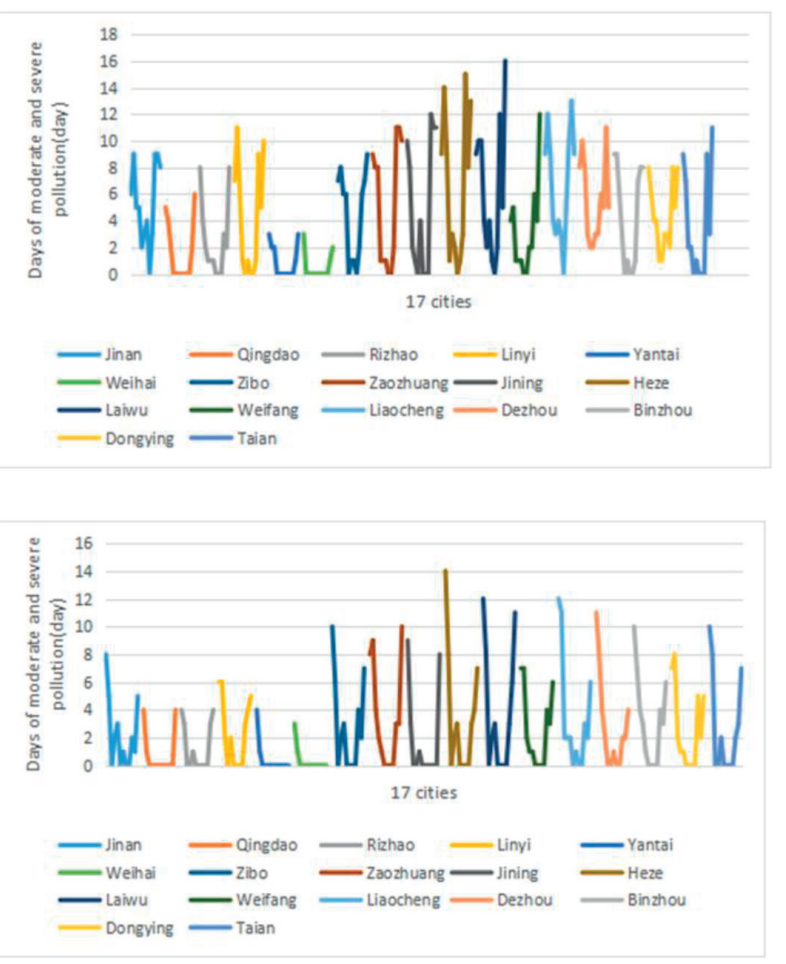

Fig. 3. Days of moderate and severe pollution in 17 cities in 2015 and 2017.

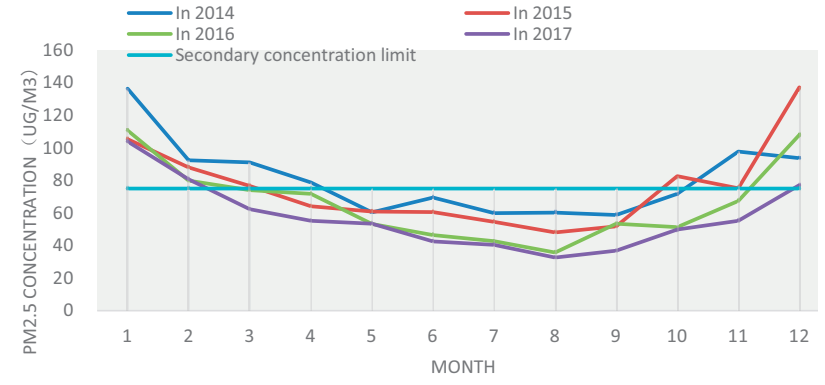

Fig. 4. Monthly PM2.5 concentration in 2014-2017.

is elevated and the precipitation is high, and the wind speed is enhanced to promote sedimentation of particulate matter.

\section{Time Series Autocorrelation}

The average daily PM2.5 concentration of $1461 \mathrm{~d}$ in Shandong Province in 2014, 2015, 2016 and 2017 was analyzed by the MATLAB statistical toolbox to reveal

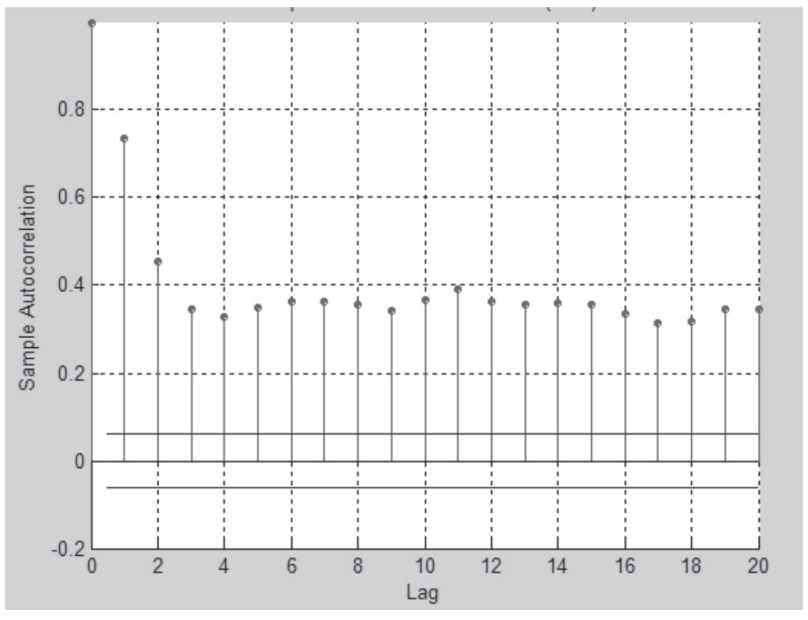

Fig. 5. Autocorrelation coefficient of the PM2.5 concentration in Shandong Province during 2014-2017. 


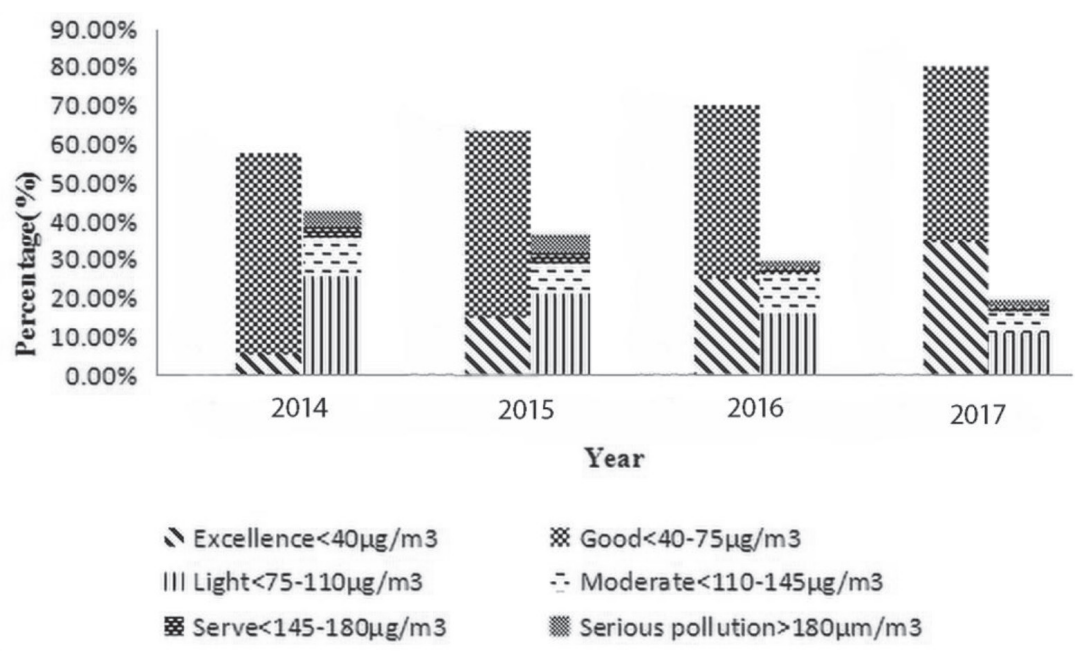

Fig. 6. Trend of PM2.5 concentration in Shandong between 2014 and 2017.

the time series characteristics of the four-year PM2.5 concentration change in Shandong Province, and the main findings are as follows (such as Fig. 5): Looking up the critical value table of the correlation coefficient, at the significant level $\alpha=0.001$, the degree of freedom is 1000 , the critical value of the correlation coefficient test is $\gamma 0.001=0.081$, and the autocorrelation coefficient of order 1-20 is larger than the critical value. The results showed that the autocorrelation of the PM2.5 concentration in Shandong Province is particularly strong with time. The farther the time is, the weaker the correlation is. The closer the time is, the stronger the correlation is. The time period of two days was the most relevant. The daily average PM2.5 concentration in Shandong Province is related to the concentration in the previous 1-20 days, and it has the strongest correlation with the first and second days.

\section{Statistics of PM2.5 Exceeding the Standard}

According to the annual average concentration limit of PM2.5 in China's "Environmental Air Quality Standards" (GB3095-2012) [42], the annual average concentration of PM2.5 can be divided into 6 intervals: excellent $\left(0-40 \mu \mathrm{g} / \mathrm{m}^{3}\right)$, good $\left(40-75 \mu \mathrm{g} / \mathrm{m}^{3}\right)$, light $\left(75-110 \mu \mathrm{g} / \mathrm{m}^{3}\right)$, moderate $\left(110-145 \mu \mathrm{g} / \mathrm{m}^{3}\right)$, severe $\left(145-180 \mu \mathrm{g} / \mathrm{m}^{3}\right)$, and serious pollution $\left(>180 \mu \mathrm{g} / \mathrm{m}^{3}\right)$. Through an in-depth analysis of the proportion in each year of the study period, the daily average concentration of PM2.5 in 17 cities of Shandong Province was calculated, and the frequency of pollution levels in each city was obtained. The number of days with excellent air quality in Shandong Province has increased year by year, with an increase of up to $35 \%$ in 2017 . The proportion of annual average PM2.5 concentrations higher than $180 \mu \mathrm{g} / \mathrm{m}^{3}$ (the serious pollution limit) continued to decline from $3.8 \%$ in 2014 to $1.4 \%$ in 2017. The results indicate that the number of low polluted areas with annual average PM2.5 concentrations less than $40 \mu \mathrm{g} / \mathrm{m}^{3}$ increased continuously, while the number of high polluted areas with an average annual concentration of PM2.5 higher than $110 \mu \mathrm{g} / \mathrm{m}^{3}$ increased. The number of days in which air quality reached the standard in the 17 cities rose between 2014 and 2017 from 210 days to 294 days. The air compliance rate is as high as $81 \%$ per day. Fig. 6 shows that the Shandong Provincial Party Committee and the provincial government issued a comprehensive plan for solving key environmental protection issues in 2017, which will greatly help improve the environmental quality of Shandong Province.

\section{Evolution Characteristics of PM2.5 Spatiotemporal Patterns in Shandong Province}

\section{Evolution Characteristics of Spatial-Temporal Patterns}

The global autocorrelation of PM2.5 concentrations in 17 counties and cities of Shandong Province was analyzed by using GeoDa software for 2015 and 2017. As shown in Table 1, the global autocorrelation coefficient of Moran's I index was higher in 2017 than

Table 1. Global spatial autocorrelation coefficient of PM2.5 concentration in Shandong.

\begin{tabular}{|c|c|c|c|}
\hline Date & Moran's I & Z value & P value \\
\hline Winter of 2015 & 0.5318 & 3.4860 & 0.002 \\
\hline Spring of 2015 & 0.5032 & 3.3216 & 0.003 \\
\hline Summer of 2015 & 0.6453 & 3.9573 & 0.001 \\
\hline Autumn of 2015 & 0.65091 & 4.058 & 0.001 \\
\hline Winter of 2017 & 0.6006 & 3.9233 & 0.001 \\
\hline Spring of 2017 & 0.5582 & 3.6425 & 0.002 \\
\hline Summer of 2017 & 0.6988 & 4.4092 & 0.001 \\
\hline Autumn of 2017 & 0.5638 & 3.6671 & 0.004 \\
\hline
\end{tabular}


in 2015, except in autumn. The $\mathrm{Z}$ value of the overall autocorrelation coefficient in each period coincides with the Moran's I index. During the study period, the

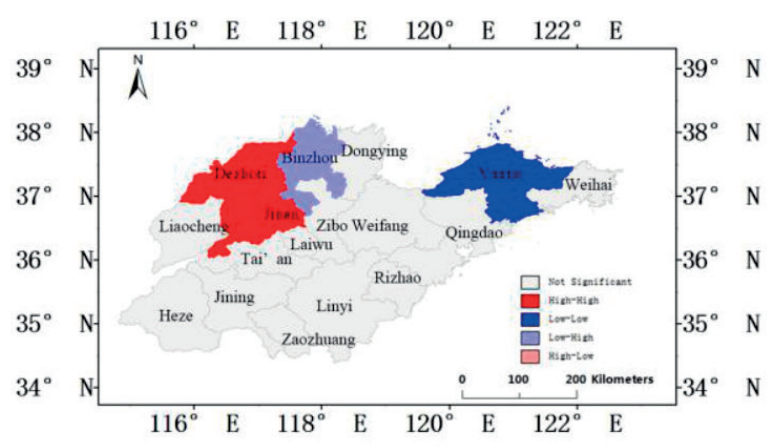

a) Winter of 2015

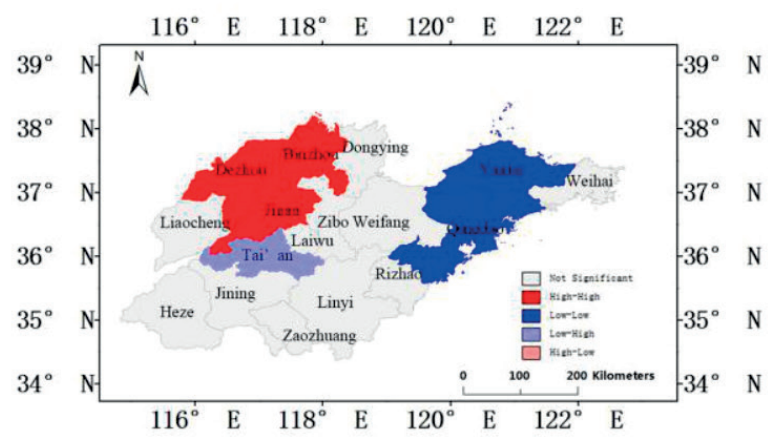

c) Summer of 2015

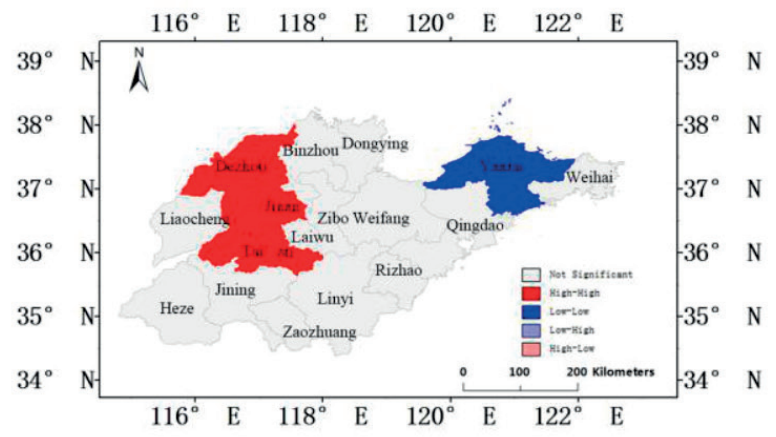

e) Winter of 2017

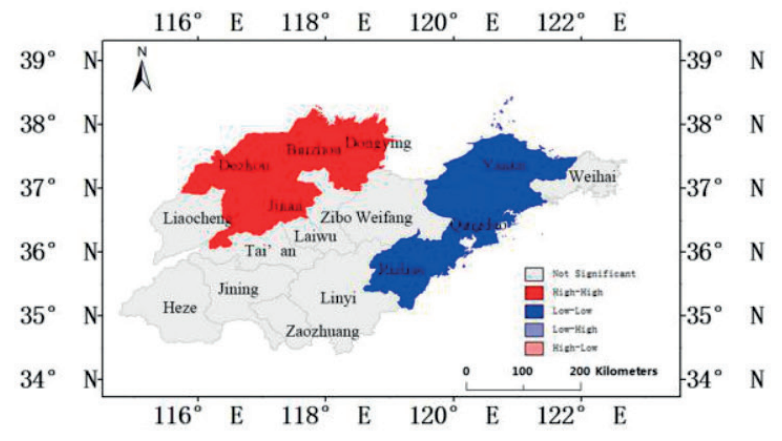

g) Summer of 2017 global Moran's I index is positive, the $\mathrm{Z}$ value is greater than 2.58, and the $\mathrm{P}$ value is less than 0.01 . Thus, the global positive spatial autocorrelation of the PM2.5

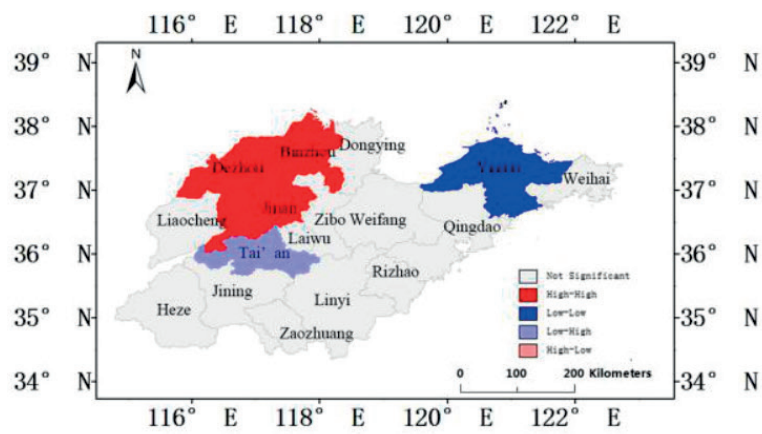

b) Spring of 2015

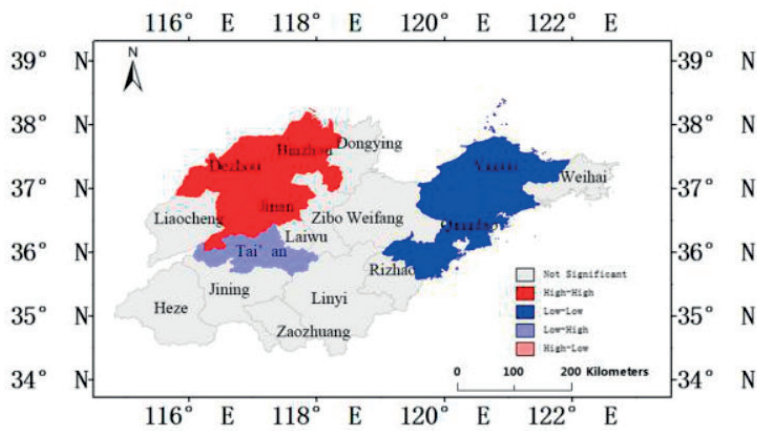

d) Autumn of 2015

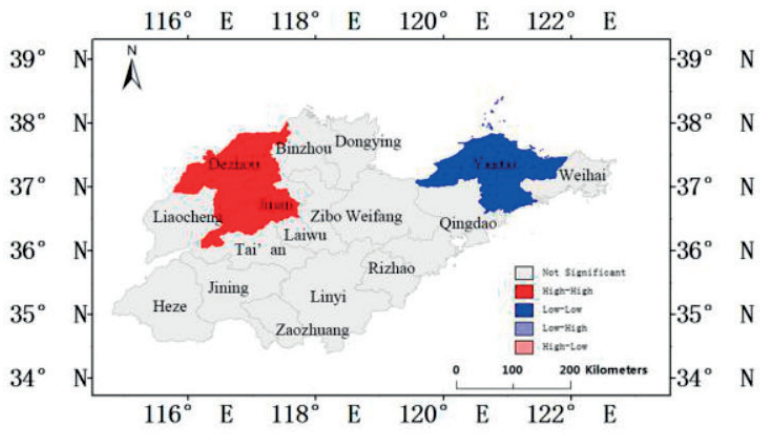

f) Sping of 2017

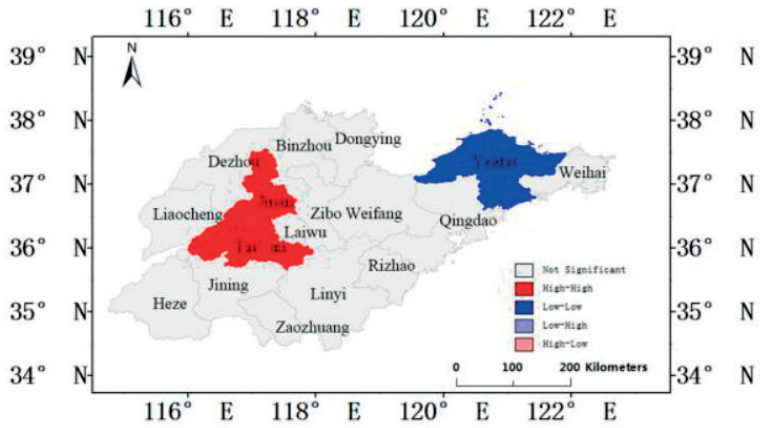

h) Autumn of 2017

Fig. 7. Local spatial autocorrelation of PM2.5 in Shandong Province in 2015-2017. 
annual average concentration in Shandong Province is significant, and the spatial aggregating feature is obvious. A local autocorrelation analysis was conducted on the 2015-2017 average concentrations of 17 counties and cities in Shandong Province using GeoDa software. As shown in Fig. 7, aggregation was low-low in Yantai in all periods of time; low-low in Qingdao in the third quarter of each year, that is, autumn; high-high in Jinan; and always in the transition between low-high and high-high in Tai'an. The PM2.5 concentration in other counties and cities did not show meaningful local spatial autocorrelation. In 2017, no county or city with a "high-low" or "low-high" local spatial autocorrelation type was found, which indicated that the PM 2.5

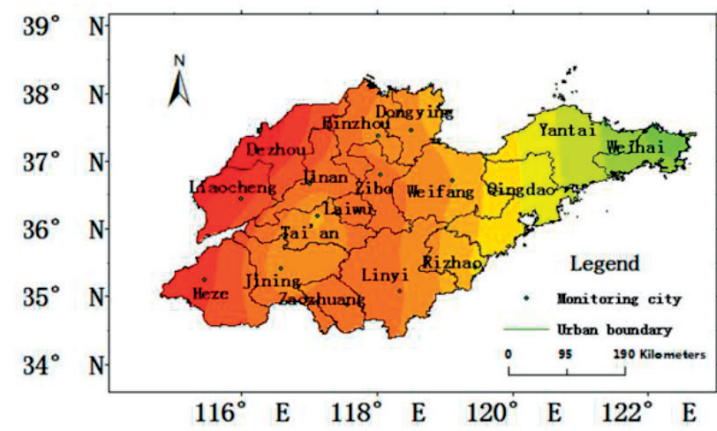

a)Winter of 2015

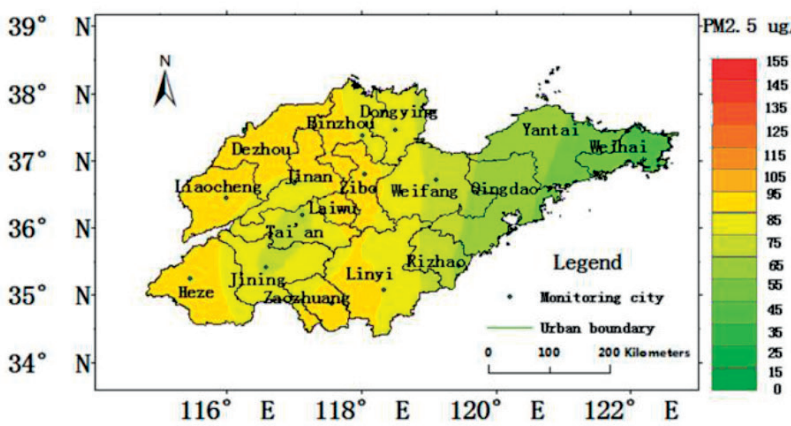

b)Spring of 2015

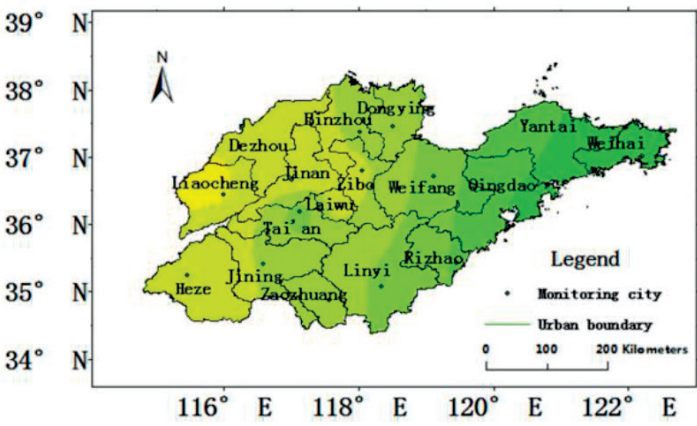

c)Summer of 2015

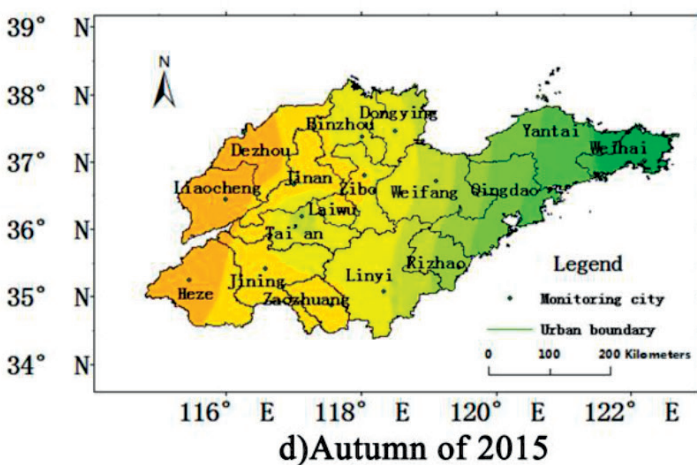

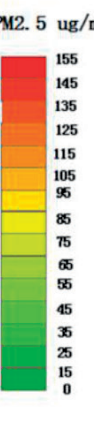
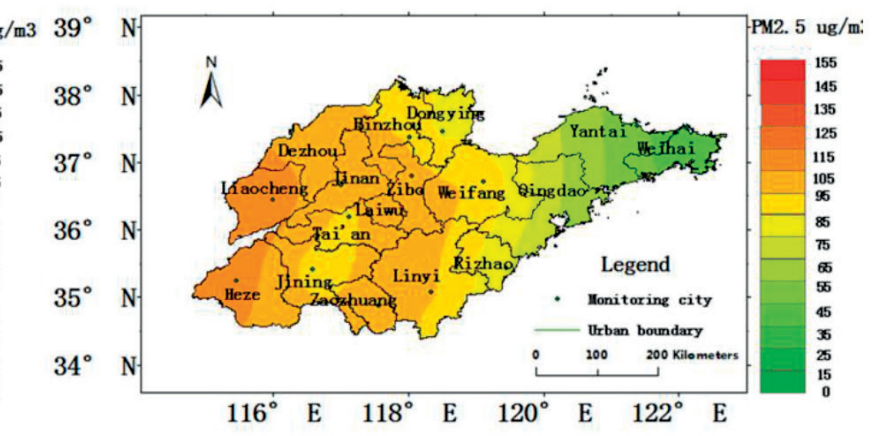

e)Winter of 2017

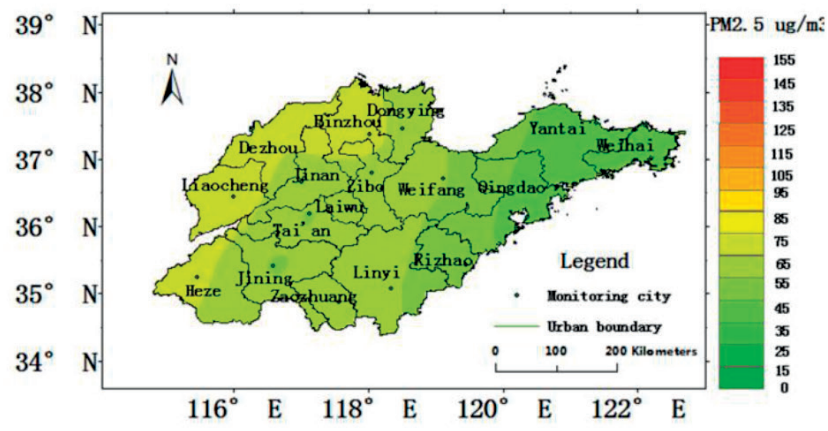

f)Spring of 2017
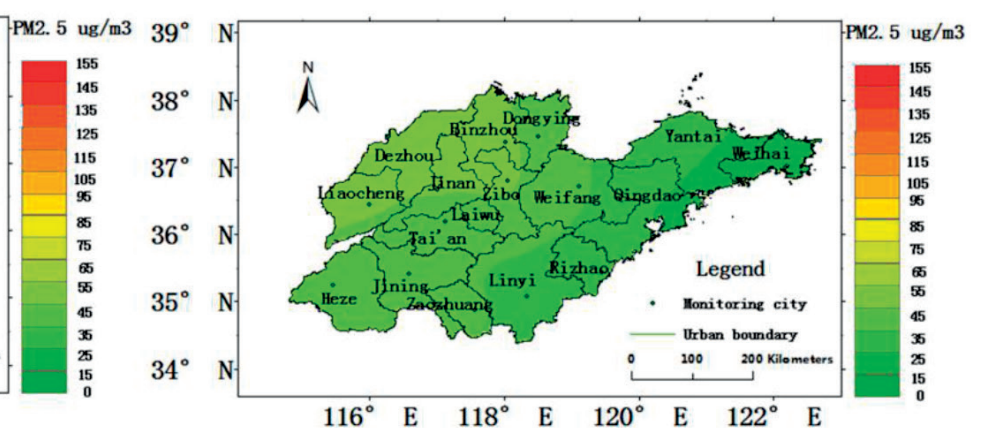

g)Summer of 2017

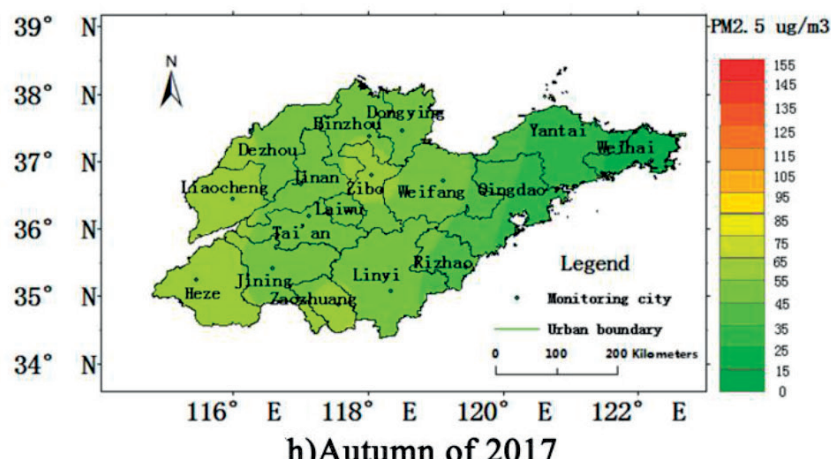

h)Autumn of 2017

Fig. 8. The spatial distribution of PM2.5 concentrations in Shandong Province in 2015 and 2017. 
concentration in Shandong Province shows strong positive local spatial autocorrelation characteristics.

\section{Spatial Distribution Patterns of PM2.5} Concentration in Shandong Province

Interpolation is one of the main research contents of geostatistics. Cities are the agglomeration of economy, architecture, population and traffic, resulting in high PM2.5 concentrations in many developed urban areas. In this paper, the spatial interpolation method is used for real-time monitoring point data. However, most of the air quality monitoring stations are located in cities, with a small number in rural areas. Scholar Chen Di concluded that the change in PM2.5 at all monitoring stations in China has a global correlation through principal component analysis and further established that the PM2.5 at each monitoring station has a long-range correlation through the spatial distance correlation coefficient. It seems that the concentration of PM2.5 in each city is a random variable [43]. The actual concentration of PM2.5 is continuous and regular in space. The kriging interpolation method is based on the theory of variation function and structural analysis, and it is a method for unbiased optimal estimation of the value of regionalism variables in a limited area .

The ARCGIS10.2 software geostationary analysis toolbox was used for interpolation analysis. According to the principle of minimum error, verified and crossvalidated multiple experiments, ordinary kriging spatial interpolation analysis was carried out for the quarterly PM2.5 concentration in Shandong Province for 2015 and 2017 with small errors and better results (Fig. 8).

The concentration of PM2.5 in Shandong Province showed a spatial distribution trend of high in the west and low in the east. The concentration of PM2.5 gradually increased from the coastal to inland areas, showing a stepped change. The most noticeable change was in the winter of 2015. Extra-high pollution areas with concentrations above $155 \mu \mathrm{g} / \mathrm{m}^{3}$ were concentrated in Liaocheng, Heze and Dezhou. At this time, the concentration of Weihai City in the eastern part of
Shandong Province was less than $28 \mu \mathrm{g} / \mathrm{m}^{3}$, and the difference between the two concentrations was nearly fivefold. The concentration in Tai'an City was 90$100 \mu \mathrm{g} / \mathrm{m}^{3}$, except in winter. In Tai'an City, most of the mountains have a blocking effect on the large amount of fine particles carried around the surrounding area, so the air quality is better. In terms of seasonal distribution, the PM2.5 concentration for each quarter in 2017 substantially improved and was higher than that in 2015, but the concentration in winter was greater than that in other seasons. The northwest wind prevails in Shandong Province in winter. In addition to its own emissions of fine particles, the upper wind in Beijing, Tianjin and Hebei also carries large amounts of fine particles. With blockage in the central mountainous areas of Shandong Province, the PM2.5 concentration in Shandong Province increased to a certain extent. The prevailing summer monsoon became the southeast monsoon, and the wind from the ocean diluted the pollutants discharged by Shandong Province itself. Winter coal consumption is among the reasons for the increase in PM2.5 concentration. People are becoming increasingly aware of the hazards of PM2.5; thus, coal consumption has been reduced to protect the environment, high pollution areas in Shandong Province have shown a rapid reduction in pollution, and the environmental quality has been effectively improved.

\section{Analysis of Driving Factors of PM2.5 Pollution in Shandong Province}

The accuracy of pollution source analysis determines the reliability of environmental impact prediction results and provides important measures for pollution prevention and control. The pollution sources of PM2.5 in Shandong Province involve many complicated impact factors. This paper selects data from 17 cities in 2014, 2015, 2016 and 2017 to explore the advantages of geographic detectors in detecting spatial differentiation characteristics and patterns and reveals the driving factors behind them. Eight indicators, namely, crop broadcast area (X1), physical geographical division

Table 2. Geographical detection analysis of PM2.5.

\begin{tabular}{|c|c|c|c|c|c|c|c|c|}
\hline Detection index & \multicolumn{2}{|c|}{2014} & \multicolumn{2}{|c|}{2015} & \multicolumn{2}{|c|}{2016} & \multicolumn{2}{|c|}{2017} \\
\hline & $\mathrm{P}$ & $\mathrm{Q}$ & $\mathrm{P}$ & $\mathrm{Q}$ & $\mathrm{P}$ & $\mathrm{Q}$ & $\mathrm{P}$ & $\mathrm{Q}$ \\
\hline Crop broadcast area (X1) & 0.6357 & 0.1698 & 0.9526 & 0.2444 & 0.9693 & 0.1645 & 0.9193 & 0.1815 \\
\hline Natural geographical division (X2) & 0.5957 & 0.1468 & 0.6072 & 0.2916 & 0.7144 & 0.2528 & 0.5699 & 0.3418 \\
\hline Built-up area proportion (X3) & 0.3432 & 0.2720 & 0.3743 & 0.3750 & 0.9088 & 0.3044 & 0.6315 & 0.3689 \\
\hline Urban greening rate (X4) & 0.9983 & 0.0090 & 0.4483 & 0.3488 & 0.9860 & 0.1678 & 0.9931 & 0.1568 \\
\hline Gas and petroleum gas supply (X5) & 0.2219 & 0.3004 & 0.4466 & 0.3301 & 0.3007 & 0.4862 & 0.1536 & 0.6174 \\
\hline Residential car ownership (X6) & 0.4922 & 0.3052 & 0.0949 & 0.4485 & 0.1093 & 0.4358 & 0.1220 & 0.4275 \\
\hline Smoke and dust emission (X7) & 0.9552 & 0.0914 & 0.9184 & 0.2000 & 0.9949 & 0.0543 & 0.9415 & 0.0806 \\
\hline Population density (X8) & 0.6945 & 0.1812 & 0.6386 & 0.1497 & 0.5372 & 0.1980 & 0.5864 & 0.1705 \\
\hline
\end{tabular}


(X2), built-up area proportion (X3), urban greening rate (X4), gas and petroleum gas supply (X5), residential car ownership (X6), smoke and dust emission (X7), and population density $\mathrm{X} 8$ ), were selected to calculate the contribution of PM2.5 in 17 cities of Shandong Province (Table 2).

\section{Natural Factors Driving Temporal and Spatial Variations in PM2.5}

The change in PM2.5 concentrations in Shandong Province determined by a geographic detector is closely related to regional natural factors. The most significant factor impacting PM2.5 is the natural geographic region (X2). For the three years of 2014,2015, 2016 and 2017, the detection and explanatory power $\mathrm{P}$ values of PM2.5 are 0.5957,0.60723, 0.71438 and 0.56993, respectively, which fully shows the pattern of regional differentiation. Hydrology and vegetation have an important effect on the formation mechanism of PM2.5. The spatial and temporal pattern identified two heavy PM2.5 pollution areas in Liaocheng and Dezhou, Shandong Province, and Tai'an is a light pollution area. Geographical location is an important factor affecting urban air quality. Shandong Province is dominated by the northwest monsoon in winter and is adjacent to the Beijing-Tianjin-Hebei region with high concentrations. The diffusion and transmission of particulate matter to the Liaocheng area is an important factor leading to the increased concentrations in Liaocheng [44]. The eastern and northern regions of Tai'an City are mountainous areas, which are significantly different from the surrounding cities, and the southeast and northwest winds prevail all year round. The favorable combination of geographical and meteorological conditions prevents the PM2.5 concentration from increasing. The particulate matter from the northwest can be easily diluted with time and decreased air pressure. Tai'an City has strong pollution control policies for industry, automobile exhaust and other aspects, which together form good urban air quality. Coastal areas are markedly affected by the ocean monsoon, rivers and water masses. The humid and windy climate and the concentration of diluted particulate matter are conducive to purifying the air. In winter, due to the regulation of sea-land circulation, rain and snow increases. Rain and snow can remove dust in the air and dissolve the absorbable exhaust gas. Therefore, coastal areas have good air quality and low PM2.5 concentrations.

\section{Analysis of Socioeconomic Factors Driving Spatiotemporal Changes in PM2.5}

Atmospheric pollution is not only deeply affected by human activities but also driven by dust generated by the urbanization process, exhaust emissions caused by the increase in automobiles, coal-fired heating, and straw burning caused by agricultural production in the process of urbanization $[45,46]$. In addition to being strongly influenced by natural factors, 17 cities in Shandong Province are also affected by social and economic factors.

Driven by urbanization construction. The analysis of urban development and urban construction factors driving the change in PM2.5 concentration by geographic detectors shows that the detection $\mathrm{P}$ values of urban population density (X8) for PM2.5 in 2014,2015, 2016 and 2017 are $0.69450 .63863,0.53718$ and 0.58640 , respectively, showing the characteristics of "U"-type change. The detection $\mathrm{P}$ values of the urban greening rate (X4) were $0.44833,0.98604$ and 0.99307 , respectively. The results showed that the contribution rate to the change in PM2.5 concentration gradually increased with increasing greening rate. The detection $\mathrm{P}$ values of the area ratio (X3) of the built-up area are $0.99830 .37427,0.90883$ and 0.63154 , respectively, showing the characteristics of inverted "U"-type change. Therefore, urban population density, urban greening rate and area ratio are key factors that affect changes in the PM2.5 concentration.

Driven by motor vehicle exhaust and smoke emission. The analysis of vehicle factors driving the change in PM2.5 concentration by geographic detectors shows that the detection $\mathrm{P}$ values of resident car ownership (X6) are 0.4922, 0.09490, 0.10925 and 0.12198 in the four time sections of 2014, 2015, 2016 and 2017, respectively. Car ownership had nonsignificant effects on the PM2.5 concentration in 2015 and 2017, and smoke and dust emissions (X7) had the most significant influence on PM2.5. In 2014, 2015, 2016 and 2017, the detection and explanatory power P values for PM2.5 were 0.9552, 0.91838, 0.99485 and 0.94152 , respectively, showing an inverted U-shaped distribution. Nevertheless, smoke emissions had a greater influence on PM2.5 concentration changes. Soot is a solid particulate matter emitted per coalfired and industrial production processes. The dust pollution intensity is high and widespread, and it is an important source of pollution for the increase in PM2.5 concentration.

Driven by straw combustion. Geographic detector analysis showed that crop sowing areas indirectly represented straw burning. In the three time sections of 2014, 2015, 2016 and 2017, the detection P values of crop sowing areas (X1) for PM2.5 were 0.6357, 0.95257, 0.96932 , and 0.91932 , respectively, showing an inverted "U" pattern. The maximum concentration of PM2.5 by straw burning reached 0.96932 in 2016 and then showed a downward trend. For this reason, the environmental protection department of Shandong Province takes straw burning as a key task in summer and autumn every year to improve the environment.

Driven by winter heating. In northern Shandong Province, winter heating is likewise a factor affecting the PM2.5 concentration. Geographic detector analysis of heating area factors driving the change in the PM2.5 concentration shows that the detection $\mathrm{P}$ values of the heating area were $0.2219,0.44661,0.30070$ and 0.15362 
in four time sections of 2014, 2015, 2016 and 2017, respectively, showing a gradual decrease. Similarly, winter heating had a relatively small influence. In northern China, coal burning for heating in winter and pollutant particle discharge into the atmosphere are responsible for the increased concentration in winter.

\section{Discussion}

The temporal and spatial variation of the PM2.5 concentration in the atmosphere provides a basis for predicting and controlling air pollution in Shandong Province. In terms of collected data, the daily monitoring values of air pollutants are crucial because they are more scientific and accurate.

Geographic detectors show remarkable effectiveness for detecting the driving forces of PM2.5 among natural and socio-economic factors. In addition to climate, wind speed, topography and other natural reasons, soil dust, motor vehicle exhaust, coal combustion, industrial emissions and so on are important influences. Among these, human factors such as straw burning are important driving factors. Geographic detectors are mainly used to analyze the driving forces of various phenomena and the interactions of various factors.

Finally, we focus on the analysis of PM2.5 concentration changes and influences in Shandong Province from 2014 to 2017. All of the discussions of time, space and driving forces are based on these data. Wang Zhenbo and other scholars ranked cities only for PM2.5 concentration and concluded that the 10 cities with the highest PM2.5 average value were Xingtai, Baoding, Shijiazhuang, Handan, Hengshui, Dezhou, Heze, Tangshan, Liaocheng and Langfang [47]. Among these cities, three are located in Shandong Province: Dezhou, Heze and Liaocheng. Therefore, it is urgent to improve the air quality in Shandong Province. To fundamentally solve the problem of PM2.5 pollution, we must formulate relevant policies, industrial structures and energy structures from PM2.5 pollution sources, including promoting supply-side reform, reducing overcapacity, improving supply quality and efficiency, and focusing on intelligent, green and service-oriented development of the manufacturing industry to improve energy efficiency. We will vigorously develop clean new energy sources, reduce the proportion of overall coal in energy consumption, increase the control of existing pollution industries, and encourage enterprises to incorporate new technologies.

\section{Conclusions}

From 2014 to 2017, the annual concentration of PM2.5 in Shandong Province showed a significant and sustained downward trend. The average concentration in Shandong Province dropped from $80.9 \mu \mathrm{g} / \mathrm{m}^{3}$ in 2014 to $57.6 \mu \mathrm{g} / \mathrm{m}^{3}$ in 2017. The concentration of PM2.5 in
Shandong Province has a significant "U"-type monthly change pattern. From 2014 to 2017, the number of air quality standard days in 17 cities increased from 210 days to 294 days. Ultimately, the air standard rate reached $81 \%$. The number of orthodox days was the highest in summer, followed by spring, and the lowest number was in winter. The autocorrelation coefficient of the PM2.5 concentration time series is high, and the first-order autocorrelation coefficient is as high as 0.75 .

PM2.5 in Shandong Province follows an obvious spatial agglomeration law, with a trend of high values in the west and low values in the east in the spatial distribution in 2015 and 2017. The concentration of PM2.5 gradually increased from coastal to inland areas, showing a stepped change. high-polluted areas in Shandong Province showed a tendency of rapid reduction, and the global autocorrelation was extremely significant. There was the spatial concentration of PM2.5 in Shandong Province in 2015 and 2017, and Yantai City had a low-low concentration in all time periods. In autumn, Qingdao increased; Jinan and Dezhou had a high-high agglomeration; Tai'an was always between low-high agglomeration and high-high agglomeration; and the local spatial autocorrelation of PM2.5 concentration in other urban areas was not significant.

Analysis of the driving factors shows that both natural factors and social factors have an impact on the evolution of the spatial characteristics of PM2.5 pollution, among which smoke and dust emissions and straw burning have the most significant driving effect on PM2.5. The main driving factors for the change in PM2.5 concentration in Shandong Province are physical geographical division, proportion of built-up area, urban greening rate, heating area and population density.

\section{Acknowledgements}

This research was funded by the National Natural Science Foundation of China (Grant No. 41801308, 51608309) and Shandong Social Science Planning Project (14DGLJ06).

\section{Conflict of Interest}

The authors declare no conflict of interest.

\section{References}

1. HE X., LIN Z.S., LIU H.Y. Analysis of Influencing Factors and System Evolution of PM2.5 Concentration Change Based on Statistical Dynamic Inversion Model. Ecol Environ Sci. 26 (11), 1916, 2017.

2. KAN H., CHEN R.J., TONG S.L. Ambient air pollution, climate change, and population health in China. Environ Int. 42, 10, 2012. 
3. OPE III C.A. Review: Epidemiological basis for particulate air pollution health standards. Aerosol Sci Technol. 32 (1), 4, 2010.

4. RD POPE C., BURNETT R.T., THUN M.J., CALLE E.E., KREWSKI D., ITO K., THURSTON G.D. Lung cancer, cardiopulmonary mortality, and long- term exposure to fine particulate air pollution. JAMA. 287 (9), 1132, 2002.

5. World Health Organization. Mortality and Burden of Disease from Ambient Air Pollution. 2018. https://www. who.int/gho/phe/outdoor_air_pollution/burden/en/.

6. LIAO Z.H., SUN J.R., FAN S.J., WU D., REN M.Z., ZHOU J. Variation characteristics and influencing factors of air pollution in Pearl River Delta area from 2006 to 2012. Chin Environ Sci. 35 (2), 329, 2015.

7. ZENG X.G., RUAN F.F., PENG Y.Y. Health effects' spatial distribution analysis of PM2.5 pollution in China based on spatial grid scale. Chin Environ Sci. 39 (6), 2624, 2019.

8. LIU J.T., RUAN Y., WU Q., MA Y.L., HE X.T., LI L.Y., LI $\mathrm{S}$. Has the mortality risk declined after the improvement of air quality in an ex-heavily polluted Chinese cityLanzhou?. Chemosphere. 242, 1, 2020.

9. MORAWSKA L., AFSHAIR A., BAE G.N., BUONANNO G., CHAO C.Y.H., HANNINEN O., HOFMANN W., ISAXON C., JAYARATNE E.R., PASANEN P., SALTHAMMER T., WARING M., WIERZBICKA A. Indoor aerosols: from personal exposure to risk assessment. Indoor Air. 23, 462, 2013.

10. VICENTE E.D., VICENTE A.M., EVTYUGINA M., ODUBER F.I., AMATO F., QUEROL X., ALVES C. Impact of wood combustion on indoor air quality. Sci. Total Environ. 705, 135, 2019. https://doi.org/10.1016/j. scitotenv.2019.135769

11. CETIN M., SEVIK H., SAAK A. Indoor Air Quality: the Samples of Safranbolu Bulak Mencilis Cave. Frese Environ Bull. 26 (10), 5965, 2017.

12. YANG FS., YANG X.M., WANG Z.H., QI W.J.,LI Z.,MENG F. Geographic det5ection of impact factors of economic differences among typical counties in Jiangxi Province. Journal of Geo-information Science. 20 (1), 79, 2018.

13. LI J.T., LIU Y.S., YANG Y.Y., LIU J.L. Spatial-temporal characteristics and driving factors of urban construction land in Beijing-Tianjin-Hebei region during 1985-2015. Geographical Research. 37 (1), 37, 2018.

14. WANG J., QIU C., LIU H.B., CAO J., WANG D.C., DONG X.G. Characteristics of air quality and the correlation between API and meteorological elements in major cities of Shandong province. Ecol. Environ Sci. 22 (4), 644, 2013.

15. CETIN M., SEVIK H., ISINKARALAR K. Changes in the particulate matter and $\mathrm{CO}_{2}$ concentrations based on the time and weather conditions: the case of Kastamonu. Oxidation Communications. 40 (1), 477, 2017.

16. HAN X.D., FANG W., LI H.J., WANG Y., SHI J.L. Heterogeneity of influential factors across the entire air quality spectrum in Chinese cities: A spatial quantile regression analysis. Environ Pollut. 262, 1, 2020. https:// doi.org/10.1016/j.envpol.2020.1 14259

17. LI J.X., LIU X.S., LIU J., HUANG J. Prediction of PM2.5 concentration based on MRMR-HK-SVM model. Chin Environ Sci. 39 (6), 2304, 2019.

18. YANG W.Y., LIU Y.F., LIU Y.L., AN Z.H., YIN C.H. Investigating the Effect of Urban Landscape Pattern on PM2. 5 Concentration Based on LUR Model: A ChangZhu-Tan Urban Agglomeration Case Study. Res Environ in the Yangtze Basin. 28 (9), 2251, 2019.
19. ZHOU L., ZHOU C.H., YANG F., WANG B. SUN D.Q. Spatio-temporal evolution and the influencing factors of PM2.5 in China between 2000 and 2011. Acta Geographica Sinica, 72 (12), 2079, 2017.

20. QUEROL X., ALASTUEY A., RUIZ C.R., ARTINANO B., HANSSON H.C., HARRISON R.M., BURINGH E., TEN BRINK H.M., LUTZ M., BRUCKMANN P., STRAEHL P., SCHNEIDER J. Speciation and origin of PM10 and PM2.5 in selected European cities. Atmos Environ. 38, 6547, 2004

21. BELL M.L., DOMINICL F., EBISU K., ZEGER S.L., SAMET J.M. Spatial and Temporal Variation in PM2.5 Chemical Composition in the United States for Health Effects Studies. Environ Health Perspect. 115 (7), 989, 2007.

22. CETIN M., ONAC A.K., SEVIK H., SEN B. Temporal and regional change of some air pollution parameters in Bursa. Air Quality Atmos \& Health Air Qual Atmos Health. 12 (3), 311, 2019

23. AO X.Q., ZHENG Y., YU Y.F., WANG J.T., LI F. PM2. 5 Prediction Method Based on Multiple Time Series. J Chongqing Tech.Business Univ (Natural Science Edition). 36 (2), 41, 2019.

24. ZHAO Y.J., ZHAO T.L., YINC.Z., WANG Z.F., GE B.Z., LIU D.Y., DU X.X. Seasonal variation of the relationship between surface PM2.5 and O3 concentrations in Xuzhou. Chin Environ Sci. 39 (6), 2267, 2019.

25. FU H.C., SUN Y.L., CHEN L., ZHANG H., GAO S. MAO J., LIANG S., LI X.L.,TENG Y. Temporal and spatial distribution characteristics of PM2.5 and PM10 in Xinjiang region in 2016 based on AOD data and GWR model. Acta Sci Circumstantiae. 40 (1), 27, 2020

26. CHEN H., LI Q., ZHANG Y.H., ZHOU C.Y., WANG Z.T. Estimations of PM2.5 concentrations based on the method of geographically weighted regression. Acta Scientiae Circumstantiae. 36 (6), 2142, 2016.

27. HAN X.D., LI H.J., LIU Q., LIU F.Z., ARIF A. Analysis of influential factors on air quality from global and local perspectives in China. Environ Pollut. 248, 965, 2019.

28. WANG Z.S., LI Y.T., CHEN T., ZHANG D.W., SUN F., PAN L.B. Spatial-temporal characteristics of PM2.5 in Beijing in 2013. acta geographica sinica. 70 (1), 110, 2015.

29. GUO J.P., ZHANG X.Y., CHE H.Z., GONG S.L., AN X., CAO C.X. Correlation between pm concentrations and aerosol optical depth in eastern china. Atmos Environ. 43 (37), 5876, 2009

30. ZHANG S.P., HAN L.J., ZHOU W.Q., LI W.F. Impact of urban population on concentrations of nitrogen dioxide $\left(\mathrm{NO}_{2}\right)$ and fine particles (PM2.5) in China. Acta Ecol Sin. 36 (16), 5049, 2016.

31. JIN S.W., WU P., JI J.L. Environmental Kuznets curve (EKC) shape features in typical cities of Anhui Province and analysis of gray correlation degree. Acta Scientiae Circumstantiae. 33 (70), 2068, 2013.

32. JIANG L., ZHOU H.F., BAI L., ZHOU P. Does foreign direct investment drive environmental degradation in China? An empirical study based on air quality index from a spatial perspective. J Cleaner Production. 176, 864, 2017.

33. CHU H.J., HUANG B., LIN C.Y. Modeling the spatiotemporal heterogeneity in the PM10-PM2.5 relationship. Atmos Environ. 102 (2), 176, 2015.

34. XUE W.B., WU W.L., FU F., WANG J.N., HAN B.P., LEI Y. Satellite retrieval of a heavy pollution process in January 2013 in China. Environ Sci. 36 (3), 794, 2015. 
35. PACIOREK C.J., LIU Y. Limitations of remotely-sensed aerosol as a spatial proxy for fine particulate matter. Environ Health Perspect, 117 (6), 904, 2009.

36. Environmental Protection Department. The air quality condition of key area and74 cities in China in 2017. http:// www.zhb.gov.cn/gkml/hbb/qt/201502/t20150202_295333. htm. 2017-08-16.

37. CHEN Y.G. Geographic Data Analysis Based on MatLab. Beijing: Yi and other edu press, 2012.

38. XU J.H. Metrology geography, Yi and other education press, Beijing. 2006.

39. WANG J., CHRISTOPHERS.A. Intercomparison between satellite- derived aerosol optical thickness and PM2.5 mass:Implications for air quality studies. Geophys Res Let. 30 (21), 2095, 2003.

40. CAO L. Research on Evaluation Index System and Modeling of Regional Ecolog ical Civilization Construction.Shanghai. East China Normal Univ. 2014.

41. WANG J.F., XU C.D. Geodetector: Principle and prospective. Acta Geographica Si nica, 72 (1), 116, 2017.

42. Ministry of environmental protection of the People's Republic of China. Ambient Air Quality Standards (on trial). National Environmental Protection Standards of th e People's Republic of China (GB3095-2012), 2012-02-29

43. CHEN D., ZHANG Y.W., TIE X.X. Study on PM2.5 distribution over China using principal component analyses. Scientia Sinica Physica. 47 (2), 51, 2017.

44. ZHAO P.S., DONG F., HE D., et al. Characteristics of concentrations and chemical compositions for PM2.5 in the region of Beijing, Tianjin, and Hebei, China. Atmos Chem Physics. 13, 4631, 2013.

45. STONE B. Urban sprawl and air quality in large US cities. J Environ Manage. 86 (4), 688, 2008.

46. HUEGLIN C., GEHRIG R., BALTENSPERGER U., GYSEL M., MONN C., VONMONT H. Chemical characterisation of PM 2.5,PM 10 and coarse particles at urban, near-city and rural sites in Switzerland. Atmos. Environ. 39 (4), 637, 2005.

47. WANG Z.B., FANG C.L., XU G., PAN Y.P. Spatialtemporal characteristics of the PM2.5 in China in 2014. Acta Geographica Sinica. 70 (11), 1720, 2015. 
